\title{
Low-calorie cranberry juice supplementation reduces plasma oxidized LDL and cell adhesion molecule concentrations in men
}

\author{
Guillaume Ruel $^{1}$, Sonia Pomerleau ${ }^{1}$, Patrick Couture ${ }^{1,2}$, Simone Lemieux ${ }^{1}$, Benoît Lamarche ${ }^{1}$ and \\ Charles Couillard ${ }^{1} *$ \\ ${ }^{1}$ Institute of Nutraceuticals and Functional Foods, Department of Food Science and Nutrition, Laval University, 2440 Boulevard \\ Hochelaga, Québec, Canada G1K 7P4 \\ ${ }^{2}$ Lipid Research Center, CHUQ Research Center, CHUL Pavilion, 2705 Boulevard Laurier, Québec, Canada, GIV 4G2
}

(Received 28 March 2007 - Revised 27 June 2007 - Accepted 29 June 2007)

\begin{abstract}
Elevated circulating concentrations of oxidized LDL (OxLDL) and cell adhesion molecules are considered to be relevant markers of oxidative stress and endothelial activation which are implicated in the development of CVD. On the other hand, it has been suggested that dietary flavonoid consumption may be cardioprotective through possible favourable impacts on LDL particle oxidation and endothelial activation. The present study was undertaken to determine the effect of the daily consumption of low-calorie cranberry juice cocktail on plasma OxLDL, intercellular adhesion molecule-1 (ICAM-1), vascular cell adhesion molecule-1 (VCAM-1) and E-selectin concentrations in men. Thirty men (mean age 51 (SD 10) years) were recruited and asked to consume increasing daily doses of cranberry juice cocktail $(125,250$ and $500 \mathrm{ml} / \mathrm{d})$ over three successive periods of 4 weeks. Plasma OxLDL and adhesion molecule concentrations were measured by ELISA before and after each phase. We noted a significant decrease in plasma OxLDL concentrations following the intervention $(P<0 \cdot 0001)$. We also found that plasma ICAM-1 $(P<0.0001)$ and VCAM-1 $(P<0.05)$ concentrations decreased significantly during the course of the study. In summary, the present results show that daily cranberry juice cocktail consumption is associated with decreases in plasma OxLDL, ICAM-1 and VCAM-1 concentrations in men.
\end{abstract}

Cranberry: Flavonoids: Oxidized LDL: Cardiovascular disease: ICAM-1: VCAM-1

CVD is the leading cause of death in North America ${ }^{1}$ and it is well recognized that LDL-cholesterol is a major risk factor associated to $\mathrm{CVD}^{2}$. However, not all CVD patients show high LDL-cholesterol concentrations and it has been shown that variations in the physical properties and composition of LDL particles such as LDL oxidation could explain, at least in part, the atherogenicity of $\mathrm{LDL}^{3,4}$ even in the absence of high LDL-cholesterol concentrations. As oxidized LDL (OxLDL) are not recognized by the LDL receptor but rather by scavenger receptors at the surface of sub-endothelial resident macrophages, LDL oxidation favours the unrestricted uptake of cholesterol, thereby leading to the formation of foam cells, which is the first step in the formation of the earliest atherosclerotic lesions known as fatty streaks ${ }^{2}$.

Migration of monocytes from the bloodstream into the subendothelial space requires that cell adhesion molecules such as the intercellular cell adhesion molecule-1 (ICAM-1), vascular cell adhesion molecule-1 (VCAM-1) and E-selectin be expressed by endothelial cells. This process is referred to as endothelial activation ${ }^{2}$. Interestingly, soluble forms of these different cell adhesion molecules can be measured in plasma probably as a result of the vascular endothelium breakdown, and these concentrations have been shown to correlate with cardiovascular mortality.

Numerous studies ${ }^{6-8}$ have shown that antioxidants and more specifically polyphenolic compounds can inhibit LDL oxidation, which in turn has been suggested to reduce OxLDL-induced expression of cell adhesion molecules by endothelial cells ${ }^{9,10}$. Cranberry is a potent source of different antioxidant compounds such as flavonols, anthocyanidins, proanthocyanidins $^{11,12}$, as well as resveratrol ${ }^{13}$ and phenolic acids $^{11}$. Furthermore, cranberries also contain acetylsalicylic $\operatorname{acid}^{14}$ that possesses anti-inflammatory activity and that has been shown to decrease VCAM-1 expression in vitro ${ }^{15}$. The present study was therefore undertaken in order to examine the effect of consuming increasing doses of low-calorie cranberry juice cocktail (CJC) for a period of 12 weeks on plasma concentrations of OxLDL and cell adhesion molecules in men.

\section{Material and methods}

Subjects

Thirty-one healthy and sedentary men were recruited through the media to participate in a 12 -week intervention.

Abbreviations: CJC, cranberry juice cocktail; ICAM-1, intercellular adhesion molecule-1; IкB, nuclear factor kappa B inhibitor; NF-кB, nuclear factor kappa B; OxLDL, oxidized LDL; PJ, cranberry-flavoured low-calorie placebo juice; sICAM-1, soluble intercellular adhesion molecule-1; sVCAM-1, soluble vascular cell adhesion molecule-1; VCAM-1, vascular cell adhesion molecule-1.

* Corresponding author: Prof. Charles Couillard, fax +1 418656 3423, email charles.couillard@inaf.ulaval.ca 
Inclusion and exclusion criteria are described in Table 1 Briefly, subjects had to have a waist circumference $\geq 90 \mathrm{~cm}$, a fasting plasma LDL-cholesterol concentration between 3.0 and $5.0 \mathrm{mmol} / 1$ and absence of diabetes, CVD and renal, hepatic and endocrine disorders. A written consent was provided by each volunteer to participate in the study which was approved by the Medical Ethics Committee of Laval University (project no. 2003-131). During the course of the study, one subject dropped out of the project due to personal reasons not related to the intervention. Therefore, the data presented refer to the thirty men who completed the study.

\section{Intervention}

Upon entry into the study, subjects met with a dietitian and were instructed to maintain their usual nutritional habits throughout the entire intervention. Participants were subjected to a 4-week Run-In period which consisted of consuming $500 \mathrm{ml} / \mathrm{d}$ of a cranberry-flavoured low-calorie placebo juice (PJ). During the Run-In period, participants were instructed to reduce their alcohol consumption to a maximum of one drink/d (or $<15 \mathrm{~g}$ alcohol/d) and to refrain from consuming any vitamin, antioxidant or mineral supplements. This RunIn period was followed by three 4-week periods during which subjects successively consumed $125 \mathrm{ml}$ (phase 1), $250 \mathrm{ml}$ (phase 2) and $500 \mathrm{ml}$ (phase 3) of CJC daily. These volumes were adjusted to $500 \mathrm{ml}$ liquid/d by adding 375 , 250 or $0 \mathrm{ml} \mathrm{PJ} / \mathrm{d}$ for phases 1,2 and 3 respectively. This was achieved in order to minimize the impact of incorporating increasing quantities of liquid in the daily diet of subjects and blind subjects from the level of treatment they were assigned to.

PJ and CJC were provided to the subjects in $125 \mathrm{ml}$ readyto-drink TetraBrik boxes from Tetra-Pak $\mathbb{C}$ (Richmond Hill, Ontario, Canada) that were packaged at Laval University. Both the PJ and CJC were kindly provided to us by Ocean Spray Cranberries Inc. who also monitored the packaging sessions to ensure adequate reconstitution and quality of both the PJ and CJC. A detailed description of the PJ and CJC that were used in the present study has been previously published ${ }^{16}$. In an effort to keep the subjects' sugar consumption to a minimum and limit possible detrimental changes in plasma TAG concentrations, we provided subjects with the

Table 1. Exclusion and inclusion criteria of the study

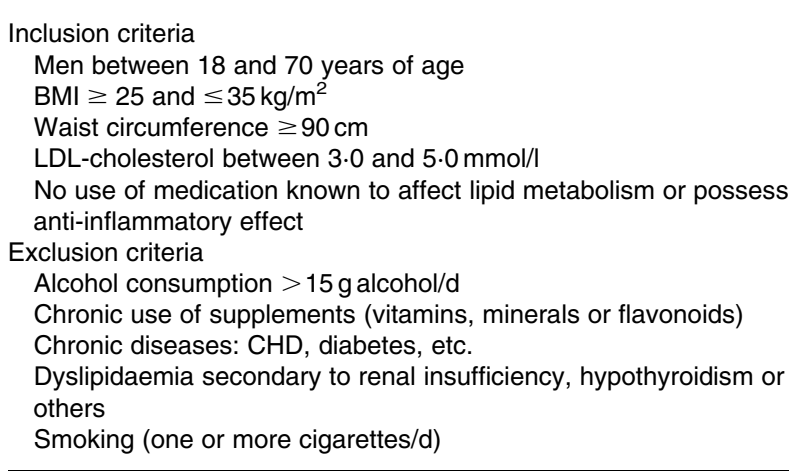

no added sugar version of Ocean Spray's Low-calorie CJC. Both the PJ and CJC were artificially sweetened with sucralose (Splenda ${ }^{\circledR}$; McNeil Nutritionals LLC, Fort Washington, PA, USA). One box of $125 \mathrm{mlCJC}$ or PJ contained $5.46 \mathrm{~g}$ of carbohydrates, and provided $91.3 \mathrm{~kJ}$ energy. A detailed description of both CJC and PJ is in Table 2.

\section{Blood pressure and lipid measures}

At each visit to the investigation unit, blood pressure was measured by a nurse with a manual sphygmomanometer with the subject in a supine position after a $5 \mathrm{~min}$ rest. Blood samples were obtained from the subjects' antecubital vein in the morning after a $12 \mathrm{~h}$ fast. Upon collection, cholesterol and TAG concentrations were determined in plasma by enzymatic methods using a Technicon RA-1000 analyser (Bayer Corporation Inc., Tarrytown, NY, USA) as previously described $^{17}$. Plasma VLDL (density $<1.006 \mathrm{~g} / \mathrm{ml}$ ) were isolated by ultracentrifugation and the HDL fraction was obtained after precipitation of LDL from the infranatant (density $>1.006 \mathrm{~g} / \mathrm{ml}$ ) with heparin and $\mathrm{MnCl}_{2}{ }^{18}$. The cholesterol and TAG contents of the infranatant fraction were measured before and after the precipitation step. LDL-cholesterol was obtained by substracting the HDL-cholesterol concentration from the cholesterol content of the density $>1.006 \mathrm{~g} / \mathrm{ml}$ fraction. Apolipoprotein (apo) B concentration was measured by nephelometry (Dade Behring, Mississauga, Ontario, Canada) in total plasma as well as in the density $<1.006 \mathrm{~g} / \mathrm{ml}$ fraction (LDL-apo B). The lyophilized serum standards for apo B measurements were prepared at the Lipid Research Center of Laval University Medical Center and calibrated with reference standards obtained from the Centers for Disease Control (Atlanta, GA, USA). Commercial ELISA kits were used to determine plasma soluble forms of E-selectin, ICAM-1, VCAM-1 (R\&D Systems, Minneapolis, MN, USA) as well as OxLDL (ALPCO Diagnostics, Windham, NH, USA) concentrations.

Table 2. Detailed description of the content of a portion $(125 \mathrm{ml})$ of placebo juice (PJ) and low-calorie cranberry juice cocktail (CJC) $†$

(Mean values and standard deviations for five determinations)

\begin{tabular}{lccccc}
\hline & \multicolumn{2}{c}{ PJ } & & \multicolumn{2}{c}{ CJC } \\
\cline { 2 - 3 } \cline { 5 - 6 } & Mean & SD & & Mean & SD \\
\hline Energy (kJ) & 91.3 & & 91.3 & \\
Carbohydrates (g) & 5.46 & 0.08 & & 5.46 & 0.28 \\
Ascorbic acid (mg) & 32 & & & 32 & \\
Total organic acids (g) & 0.90 & 0.01 & & 0.98 & 0.04 \\
Total phenolics (mg) & 39 & 0.09 & 100 & 6.50 \\
Total anthocyanins (mg) & ND & ND & & 5.2 & 0.68 \\
Cyanidin-3-galactoside & ND & ND & & 0.91 & 0.33 \\
Cyanidin-3-glucoside & ND & ND & & 0.08 & 0.01 \\
Cyanidin-3-arabinoside & ND & ND & & 1.3 & 0.26 \\
Peonidin-3-galactoside & ND & ND & & 1.5 & 0.09 \\
Peonidin-3-glucoside & ND & ND & & 0.24 & 0.01 \\
Peonidin-3-arabinoside & ND & ND & 1.2 & 0.09 \\
Proanthocyanidins (mg) & ND & ND & 74 & 5.21 \\
\hline
\end{tabular}

ND, none determined.

† Other ingredients included in PJ and CJC are filtered water, cranberry juice concentrate (CJC only), fructose, pectin, sodium citrate, ascorbic acid, sucralose and acesulfame-K. 


\section{Statistical analyses}

Data are presented as means and standard deviations unless stated otherwise. Treatment effect and changes between CJC doses on the different variables were determined using the MIXED model procedure for repeated measures. When needed, covariance matrix structures were treated for compound symmetry, order 1 autoregressive or Huynh-Feldt. Associations between changes in variables were quantified with Spearman correlation coefficients. Changes in men with ( $n$ 9) or without $(n$ 21) the metabolic syndrome were tested for significance using Student's paired $t$-tests. All analyses were performed with the SAS statistical package version 8.2 (SAS Institute, Cary, NC, USA) and $P \leq 0.05$ was considered significant.

\section{Results}

Subjects' physical and metabolic characteristics upon their entry into the study are presented in Table 3. As shown in Fig. 1, the intervention yielded a decrease in plasma OxLDL $(P<0.001)$, which reached significance from baseline after the $250 \mathrm{ml} / \mathrm{d}(-5.5(\mathrm{SD} 27.1) \%, P<0.05)$ and $500 \mathrm{ml} / \mathrm{d}$ $(-20.7$ (SD 21.1) \%, $P<0.001)$ phases. As reported and discussed in a previous publication by our group ${ }^{16}$, the intervention yielded a significant increase in plasma HDL-cholesterol $(P=0.0010)$ concentration but failed to significantly affect circulating TAG $(P=0 \cdot 0553)$ as well as levels of total cholesterol $(P=0 \cdot 85)$ and LDL-cholesterol $(P=0.52)$ (Table 4$)$.

The effects of consuming increasing daily doses of CJC on plasma cell adhesion molecule concentrations are illustrated in Fig. 2. We found that both soluble VCAM-1 (sVCAM-1; $P<0.05)$ and soluble ICAM-1 (sICAM-1; $P<0.0001)$ were decreased following the intervention, reductions reaching significance compared to baseline values after consumption of the $500 \mathrm{ml} / \mathrm{d}$ CJC dose for both sVCAM-1 (-6.4 (SD 11.5) $\%, P<0.01)$ and sICAM-1 ( -7.5 (SD 15.4) $\%, P=0.001)$. There was no effect of the intervention on plasma E-selectin concentrations $(P=0 \cdot 66)$.

Table 3. Baseline physical and metabolic characteristics of the thirty men

\begin{tabular}{|c|c|c|c|}
\hline Variable & Mean & SD & $\begin{array}{l}25 \text { th to } 75 \text { th } \\
\text { percentiles }\end{array}$ \\
\hline Age (years) & 51 & 10 & $46-60$ \\
\hline Weight (kg) & $85 \cdot 0$ & $11 \cdot 8$ & $78 \cdot 1-89 \cdot 2$ \\
\hline BMI $\left(\mathrm{kg} / \mathrm{m}^{2}\right)$ & $27 \cdot 8$ & 3.2 & $25 \cdot 7-28 \cdot 8$ \\
\hline Waist circumference $(\mathrm{cm})$ & $97 \cdot 9$ & $6 \cdot 4$ & $92 \cdot 5-100$ \\
\hline Waist/hip ratio & 0.95 & 0.04 & $0.92-0.99$ \\
\hline Cholesterol (mmol/l) & $5 \cdot 97$ & 0.85 & $5 \cdot 45-6 \cdot 51$ \\
\hline TAG $(\mathrm{mmol} / \mathrm{l})$ & 1.64 & 0.76 & $1 \cdot 31-1 \cdot 75$ \\
\hline LDL-cholesterol (mmol/l) & 4.06 & 0.70 & $3 \cdot 64-4.58$ \\
\hline HDL-cholesterol (mmol/l) & $1 \cdot 24$ & 0.26 & $1.06-1.32$ \\
\hline Cholesterol/HDL-cholesterol & 4.97 & $1 \cdot 18$ & $3.96-5.86$ \\
\hline Apolipoprotein B ( $g / l)$ & $1 \cdot 19$ & 0.23 & $1.05-1.29$ \\
\hline Oxidized LDL (U/I) & $61 \cdot 3$ & $20 \cdot 7$ & $45 \cdot 7-70 \cdot 2$ \\
\hline Soluble E-selectin (ng/ml) & $43 \cdot 1$ & 18.5 & $28 \cdot 7-59 \cdot 7$ \\
\hline slCAM-1 (ng/ml) & 191.4 & $59 \cdot 3$ & $134 \cdot 8-227 \cdot 5$ \\
\hline SVCAM-1 (ng/ml) & 425 & 61 & $385-480$ \\
\hline
\end{tabular}

sICAM-1, soluble intercellular adhesion molecule-1; sVCAM-1, soluble vascular cell adhesion molecule-1.

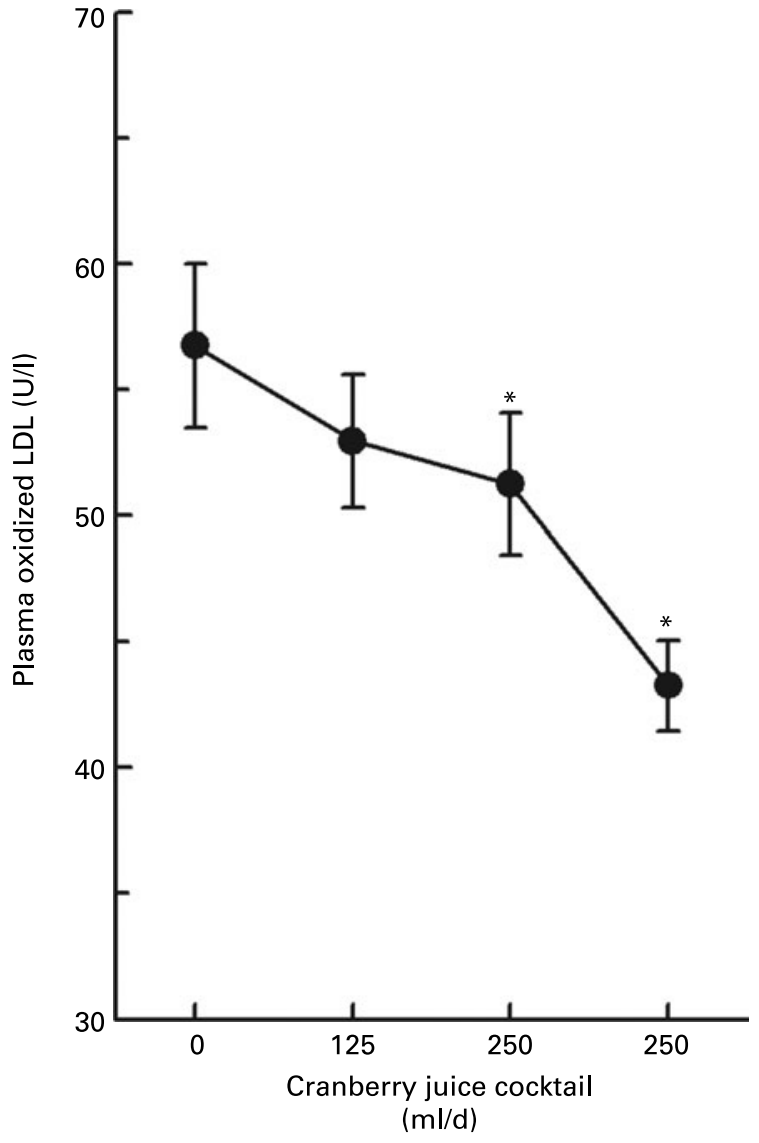

Fig. 1. Changes in plasma oxidized LDL $(P<0.0001$ across doses) concentrations during the intervention. Values are means with their standard errors depicted by vertical bars. Mean values were significantly different from baseline $(0 \mathrm{ml} \mathrm{CJC} / \mathrm{d}):{ }^{*} P<0.05$.

In an effort to characterize the relationships between the responses in plasma SVCAM-1, sICAM-1, soluble E-selectin and OxLDL concentration $(0-500 \mathrm{mlCJC} / \mathrm{d})$, we computed Spearman correlation coefficients between these variables. As shown in Fig. 3, we found a positive correlation between change in sVCAM-1 and OxLDL concentrations ( $r$ 0.62, $P<0.005)$ but an inverse association between sICAM-1 and OxLDL concentrations $(r-0 \cdot 40, P<0 \cdot 05)$.

We also examined the impact of being characterized by the metabolic syndrome, according to the National Cholesterol Education Program Adult Treatment Panel III guidelines ${ }^{19}$, on the responses of OxLDL and adhesion molecules to the intervention. As shown in Fig. 4, we found that consuming low-calorie CJC for a period of 12 weeks significantly reduced plasma OxLDL and sICAM-1 concentration in both men with and without the metabolic syndrome. However, circulating sVCAM-1 were signficantly lower at the end of the intervention only in men without the metabolic syndrome. We found no effect of the presence of the metabolic syndrome on the response of plasma soluble E-selectin concentrations to the intervention (data not shown).

As shown in Table 4, a significant variation was noted in systolic blood pressure $(P$ across doses $<0.05)$ during the intervention which was accounted for by a significant decrease between the 125 and $500 \mathrm{mlCJC} / \mathrm{d}(-7$ (SD 12) $\mathrm{mmHg}$, 
Table 4. Changes in lipids, blood pressure and heart beat during the intervention

\begin{tabular}{|c|c|c|c|c|c|c|c|c|c|}
\hline \multirow[b]{3}{*}{ Variables } & \multicolumn{8}{|c|}{ Daily cranberry juice cocktail consumption } & \multirow[b]{3}{*}{$P$ across doses } \\
\hline & \multicolumn{2}{|c|}{$0 \mathrm{ml}$} & \multicolumn{2}{|c|}{$125 \mathrm{ml}$} & \multicolumn{2}{|c|}{$250 \mathrm{ml}$} & \multicolumn{2}{|c|}{$500 \mathrm{ml}$} & \\
\hline & Mean & SD & Mean & SD & Mean & SD & Mean & SD & \\
\hline Total cholesterol (mmol/l) & $5 \cdot 84$ & $0 \cdot 76$ & $5 \cdot 90$ & 0.68 & $5 \cdot 86$ & 0.75 & $5 \cdot 82$ & 0.82 & 0.8476 \\
\hline LDL-cholesterol (mmol/l) & 4.03 & 0.64 & $4 \cdot 10$ & 0.60 & 4.04 & 0.67 & 3.97 & 0.73 & 0.5246 \\
\hline HDL-cholesterol (mmol/l) & $1 \cdot 19$ & 0.04 & $1 \cdot 23$ & 0.04 & $1 \cdot 28^{*}$ & 0.04 & $1 \cdot 28^{*}$ & 0.04 & 0.0010 \\
\hline apo B $(g / l)$ & $1 \cdot 16$ & 0.20 & $1 \cdot 19$ & 0.17 & $1 \cdot 16$ & 0.18 & $1 \cdot 18$ & 0.20 & 0.2362 \\
\hline TAG (mmol/l) & 1.57 & 0.48 & 1.43 & 0.45 & 1.44 & 0.48 & 1.49 & 0.66 & 0.0553 \\
\hline Systolic blood pressure $(\mathrm{mmHg})$ & 110 & 13 & 114 & 14 & 111 & 13 & $107^{*}$ & 10 & 0.0311 \\
\hline Diastolic blood pressure $(\mathrm{mmHg})$ & 73 & 9 & 75 & 8 & 73 & 9 & 71 & 8 & 0.2881 \\
\hline Heart beat (beats/min) & 67 & 8 & 68 & 8 & 68 & 9 & 67 & 8 & 0.9041 \\
\hline
\end{tabular}

Mean values were significantly different from those of the $0 \mathrm{ml}$ group: ${ }^{*} P<0.05$.

$P=0.0036)$ doses. On the other hand, we noted no significant change in diastolic blood pressure or heart beat in response to the 12-week intervention (Table 3).

Finally, we examined the relationships between changes in systolic blood pressure and plasma cell adhesion molecule concentrations following the intervention. A significant association was noted between change in plasma VCAM-1 concentrations and systolic blood pressure $(r \quad 0.42, P<0.05)$. However, no correlation was noted between changes in systolic blood pressure and circulating ICAM-1 $(P=0.51)$ or E-selectin $(P=0 \cdot 87)$ concentrations.

\section{Discussion}

In the present study, we report that consumption of increasing doses of low-calorie CJC on a daily basis for a period of 12 weeks is associated with reductions in plasma OxLDL as well as sICAM-1 and sVCAM-1 concentrations but has no effect on circulating E-selectin concentrations in men. It is, to our knowledge, the first time that low-calorie CJC supplementation has been associated with reductions in plasma cell adhesion molecule concentrations in man. In this sense, the present observations tend to give further support to the cardioprotective potential of cranberries that has been already suggested $^{20}$.

The significant reduction in plasma OxLDL concentrations with consumption of CJC observed in the present study is in agreement with results from previous investigations having shown that cranberry antioxidants decrease metal ion-induced LDL oxidation in vitro ${ }^{6,7}$ and with a previous study from our group in which we observed a decrease in OxLDL concentration following a 2-week CJC supplementation in men ${ }^{21}$. Consumption of other fruit juices rich in flavonoids such as grape $^{22}$ and pomegranate ${ }^{23}$, which share similarities with cranberries in regards to their polyphenolic content, has also been shown to reduce plasma OxLDL concentrations.

Although, plasma LDL-cholesterol concentrations and LDL oxidation are closely related ${ }^{24}$, the reduction in circulating OxLDL concentrations we report herein cannot be explained by changes in LDL-cholesterol concentrations as these remained stable throughout the entire intervention, as previously reported ${ }^{16}$. Furthermore, it has been shown that small dense LDL particles are more susceptible to oxidation ${ }^{25}$. Although LDL size was not measured in the present study, we have previously shown that a 2 -week CJC supplementation was not associated with any significant variation in LDL size despite a reduction in plasma OxLDL concentrations ${ }^{21}$. In addition, there was no change in the LDL-apo B/LDLcholesterol ratio, a crude marker of LDL density, during the current intervention. This suggests that LDL size may not be a major contributor to the decrease in OxLDL observed in the present study. We believe that the reduction of plasma OxLDL concentrations in response to low-calorie CJC supplementation is likely to be attributable to polyphenolic compounds of the cranberries as they exert a potent antioxidant activity ${ }^{26,27}$ and have been shown to prevent in vitro LDL oxidation $^{6,7}$. On the other hand, it may be argued that consuming low-calorie CJC may have affected the total antioxidant capacity of the subjects through increases and/or preservation of endogenous antioxidant defences. However, evidence against such changes have been recently provided with data indicating that CJC supplementation for 2 weeks had no effect on fasting blood glutathione peroxidase, catalase and superoxide dismutase activities nor on fasting circulating glutathione concentrations ${ }^{28}$. However, the possibility of improvements in these parameters over the course of the 12-week low-calorie CJC supplementation such as the one we report herein cannot be excluded.

Consumption of grape juice for $14 \mathrm{~d}$ was associated with decreases in plasma sICAM-1, an effect that was attributed to polyphenolic grapes ${ }^{29}$. The present results are supportive of the effect of polyphenols on ICAM-1 production. Interestingly, similarities exist in the polyphenol content of grapes and cranberries. Both have been characterized as potent sources of quercetin, myricetin and resveratrol ${ }^{27,30}$, which have been identified as strong antioxidants ${ }^{27}$. In contrast, other polyphenol-rich foods like tea have shown equivocal results on their effects on circulating adhesion molecule concentrations $^{31-33}$. Differences in the design of these studies but mostly in the type of flavonoids found in tea compared to cranberries are likely to explain the discrepancies between these previous observations and the present results.

The most extensively characterized pathway for cell adhesion molecule production involves the activation of NF$\kappa \mathrm{B}$. Briefly, stimulation of a phosphorylation cascade will ultimately lead to the cleavage of the nuclear factor

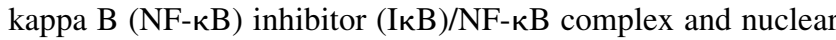
translocation of $N F-\kappa B$ where it will be able to regulate the 
A

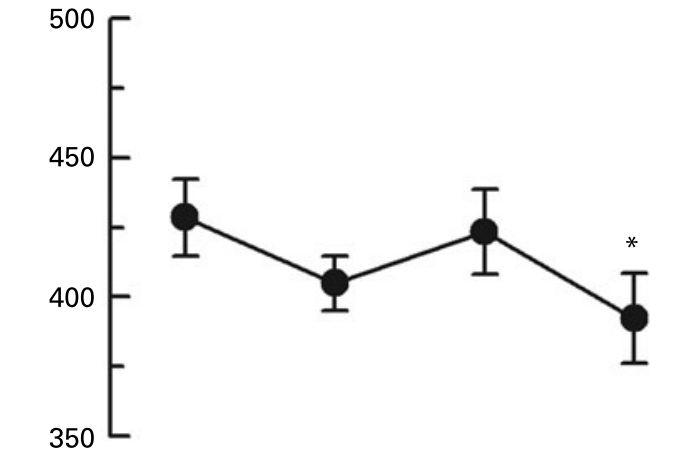

$\mathrm{B}$

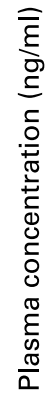

C

Fig. 2. Changes in plasma soluble vascular cell adhesion molecule-1 (A; $P<0.05$ across doses), intercellular adhesion molecule-1 (B; $P=0.0001$ ) and soluble $\mathrm{E}$-selectin $(C ; P=0.66)$ concentrations during the intervention. Values are means with their standard errors depicted by vertical bars. Mean values were significantly different from baseline $(0 \mathrm{ml} \mathrm{CJC} / \mathrm{d}):{ }^{*} P<0.05$. Mean values were significantly different from week $8(250 \mathrm{ml} \mathrm{CJC/d}): \uparrow P<0.05$.

transcription of numerous genes such as ICAM-1 and VCAM$1^{3}$. Many stimuli have been identified to activate the I $\mathrm{B} / \mathrm{NF}-$ $\kappa \mathrm{B}$ pathway including many inflammatory mediators and $\mathrm{OxLDL}^{3}$. The present observations are somewhat supportive of the OxLDL-induced production of sVCAM-1 as the change in plasma OxLDL concentration following the intervention was positively correlated to the change in circulating SVCAM1. Unfortunately, NF-кB activation was not assessed in the current study and thus our hypothesis remains to be ascertained.

On the other hand, the contribution of OxLDL to the reduction in plasma sICAM- 1 concentrations following the intervention is not so clear as we found an inverse relationship between the decrease in circulating OxLDL and sICAM-1 concentrations. Although statistically significant, the physiological relevance of that relationship remains to be better understood. Results
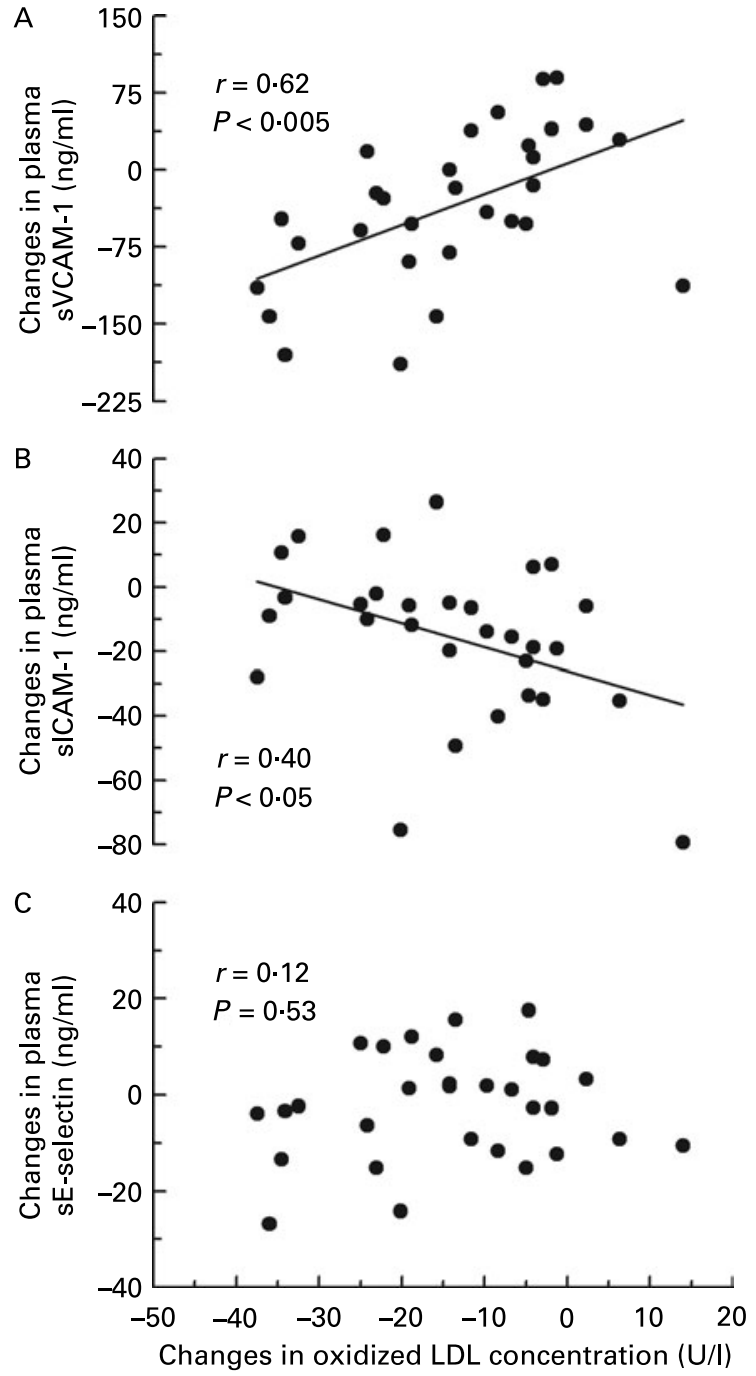

Fig. 3. Associations between changes in plasma oxidized LDL and soluble vascular cell adhesion molecule-1 (sVCAM-1; A), soluble intercellular adhesion molecule-1 (sICAM-1; B) as well as soluble E-selectin (sE-selectin; C) concentrations over the course of the entire intervention.

from in vitro studies suggest that molecules like quercetin ${ }^{34,35}$, resveratrol $^{36,37}$, proanthocyanidin $^{38}$, anthocyanidin ${ }^{39}$, hydroxycinnamic acid ${ }^{39}$ and acetylsalicylic acid ${ }^{40,41}$ have all been shown to prevent TNF- $\alpha$-induced expression of VCAM- 1 and/ or ICAM-1 through their inhibition of NF- $\kappa \mathrm{B}$ activation. Because cranberries are rich in quercetin, it is likely that the 12-week low-calorie CJC supplementation may have lowered plasma sICAM-1 through a direct effect of the increase in flavonoid intake.

Abdominal obesity is associated with a cluster of metabolic alterations including hypertriglyceridaemia, low HDL-cholesterol and impaired glucose-insulin homeostasis that has been defined as the metabolic syndrome ${ }^{42}$. Furthermore, the metabolic syndrome per se is now recognized as a risk factor of cardiovascular events ${ }^{43}$. It is therefore relevant to develop strategies aimed at improving the metabolic condition of abdominally obese individuals that could reduce their CVD risk. In the present study, we found that consuming low-calorie CJC for a period of 12 weeks significantly reduced 

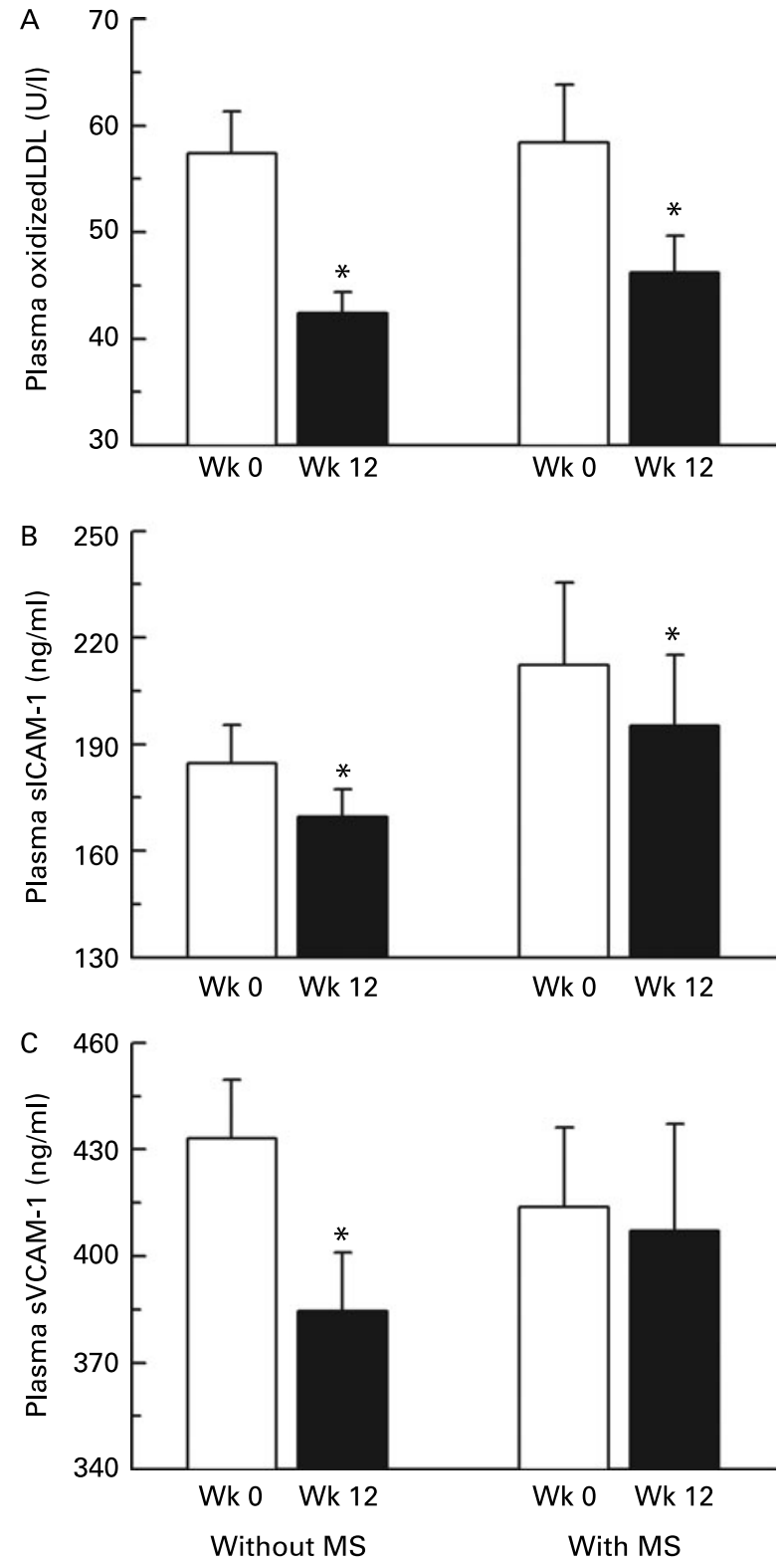

Fig. 4. Changes in plasma oxidized LDL (A), soluble intercellular adhesion molecule-1 (sICAM-1; B) and vascular cell adhesion molecule-1 (sVCAM-1; C) concentrations in response to the intervention in men with or without the metabolic syndrome (MS). Values are means with their standard errors depicted by vertical bars. Mean values were significantly different from week $0(\mathrm{Wk} 0)$ : ${ }^{*} P<0.05$.

plasma OxLDL and sICAM-1 concentrations in both men with and without the metabolic syndrome. However, our intervention yielded a significant reduction of sVCAM-1 concentrations only in subjects without the metabolic syndrome.

High blood pressure is an important risk factor for $\mathrm{CVD}^{19}$. In the present study, we noted a slight significant decrease in systolic blood pressure over the course of the intervention. We found no effect of drinking low-calorie CJC on a daily basis on diastolic blood pressure. Previous studies with fruit juice have also reported a blood pressure-lowering effect. Indeed, pomegranate $^{44}$, Concord grape juice ${ }^{45}$ and sweetie juice (mix of grapefruit and pummelo) ${ }^{46}$ in man as well as grape juice with wine vinegar in rats $^{47}$ have all been shown to lower blood pressure. Among possible mechanisms underlying the hypotensive effect of these beverages, inhibition of the activity of the angiotensin-converting enzyme has been suggested as most likely. On the other hand, dark chocolate, a food also rich in flavonoids, has been reported to increase resting brachial artery diameter ${ }^{48}$ which is concordant with a blood pressure-lowering effect. Neither angiotensin-converting enzyme activity nor brachial artery diameter were measured in the present study and the decrease in systolic blood pressure emergent herein remains unexplained.

One important drawback of the present study is that we are not able to clearly assess whether the favourable changes in plasma OxLDL, ICAM-1 and VCAM-1 concentrations we noted were the result of increasing doses of CJC or duration of the intervention. Furthermore, although a similar study design has been previously used in numerous studies ${ }^{16,21,49-53}$, the absence of a placebo control group is also unfortunate and surely imposes a limit to the present study. These issues are presently under investigation in our laboratory.

In summary, results of the present study show that a 12week supplementation with low-calorie CJC reduces plasma OxLDL concentrations in men. Furthermore, to our knowledge, the present study is the first to show that consuming low-calorie CJC leads to a decrease in circulating sICAM-1 and sVCAM-1 concentrations in man. Although further research is needed to warrant our observations, the present study reinforces the notion that consuming fruits and vegetables, or their derived products, can have significant benefits on the CVD risk profile.

\section{Acknowledgements}

This study was supported by an unrestricted grant from the Canadian Cranberry Growers Coalition. Charles Couillard, Simone Lemieux and Patrick Couture are research scholars from the Fonds de la recherche en santé du Québec (FRSQ). Charles Couillard is also supported by the Chair in Nutrition, Lipidology and Cardiovascular Disease of Laval University. Benoît Lamarche holds a Canada Research Chair in Nutrition and Cardiovascular Health. The authors had no conflicts of interest to disclose. G. R. was responsible for data collection, data analysis and drafting of the manuscript. S. P. recruited the subjects and contributed to data collection and analysis. P. C. was responsible of the medical monitoring of the subjects during the intervention. S. L. was responsible for the conception and design of the study. B. L. was responsible for the conception and design of the study and provided assistance for statistical analyses. C. C. was responsible for the conception and design of the study as well as obtaining funding for the study. All authors were also implicated in the critical review of the manuscript for important intellectual content. The authors would like to thank Marge Leahy PhD and Robin Roderick MSc from Ocean Spray Cranberries Inc. for kindly assessing the composition of CJC and placebo juice as well as supervising the packaging sessions at Laval University. We also acknowledge the contributions of Danielle Aubin (R.N) as well as Mélanie Martineau, Jocelyne Giasson, Raoul Géra, Pascal Cliche and Bernard Béliveau (Food Transformation Laboratory, Laval University). Finally, we would like to thank the subjects without whom no clinical research would be possible. 


\section{References}

1. American Heart Association (2005) Heart Disease and Stroke Statistic - 2005 Update. Dallas, TX: American Heart Association.

2. Ross R (1999) Atherosclerosis - an inflammatory disease. $N$ Engl J Med 340, 115-126.

3. Robbesyn F, Salvayre R \& Negre-Salvayre A (2004) Dual role of oxidized LDL on the NF-kappaB signaling pathway. Free Radic Res 38, 541-551.

4. Klouche M, May AE, Hemmes M, Messner M, Kanse SM, Preissner KT \& Bhakdi S (1999) Enzymatically modified, nonoxidized LDL induces selective adhesion and transmigration of monocytes and T-lymphocytes through human endothelial cell monolayers. Arterioscler Thromb Vasc Biol 19, 784-793.

5. Blankenberg S, Rupprecht HJ, Bickel C, Peetz D, Hafner G, Tiret L \& Meyer J (2001) Circulating cell adhesion molecules and death in patients with coronary artery disease. Circulation 104, 1336-1342.

6. Chu YF \& Liu RH (2005) Cranberries inhibit LDL oxidation and induce LDL receptor expression in hepatocytes. Life Sci 77, $1892-1901$.

7. Wilson T, Porcari JP \& Harbin D (1998) Cranberry extract inhibits low density lipoprotein oxidation. Life Sci 62, PL381-PL386.

8. Fuhrman B \& Aviram M (2001) Flavonoids protect LDL from oxidation and attenuate atherosclerosis. Curr Opin Lipidol 12, $41-48$.

9. Couillard C, Ruel G, Archer WR, Pomerleau S, Bergeron J, Couture P, Lamarche B \& Bergeron N (2005) Circulating levels of oxidative stress markers and endothelial adhesion molecules in men with abdominal obesity. J Clin Endocrinol Metab 90, 6454-6459.

10. Kume N, Cybulsky MI \& Gimbrone MA Jr (1992) Lysophosphatidylcholine, a component of atherogenic lipoproteins, induces mononuclear leukocyte adhesion molecules in cultured human and rabbit arterial endothelial cells. J Clin Invest $\mathbf{9 0}$, $1138-1144$.

11. Chen H, Zuo Y \& Deng Y (2001) Separation and determination of flavonoids and other phenolic compounds in cranberry juice by high-performance liquid chromatography. J Chromatogr A 913, 387-395.

12. Wang P, Du C \& Francis F (1978) Isolation and characterization of polyphenolic compounds in cranberries. J Food Sci 43, $1402-1404$.

13. Wang Y, Catana F, Yang Y, Roderick R \& van Breemen RB (2002) An LC-MS method for analyzing total resveratrol in grape juice, cranberry juice, and in wine. J Agric Food Chem 50, $431-435$.

14. Duthie GG, Kyle JA, Jenkinson AM, Duthie SJ, Baxter GJ \& Paterson JR (2005) Increased salicylate concentrations in urine of human volunteers after consumption of cranberry juice. J Agric Food Chem 53, 2897-2900.

15. Eisele G, Schwedhelm E, Schieffer B, Tsikas D \& Boger RH (2004) Acetylsalicylic acid inhibits monocyte adhesion to endothelial cells by an antioxidative mechanism. J Cardiovasc Pharmacol 43, 514-521.

16. Ruel G, Pomerleau S, Couture P, Lemieux S, Lamarche B \& Couillard C (2006) Favourable impact of low-calorie cranberry juice consumption on plasma HDL-cholesterol concentrations in men. Br J Nutr 96, 357-364.

17. Moorjani S, Dupont A, Labrie F, Lupien PJ, Brun D, Gagne C, Giguere M \& Belanger A (1987) Increase in plasma high-density lipoprotein concentration following complete androgen blockage in men with prostatic carcinoma. Metabolism 36, $244-250$.
18. Burstein M, Scholnick HR \& Morfin R (1970) Rapid method for the isolation of lipoproteins from human serum by precipitation with polyanions. J Lipid Res 11, 583-595.

19. National Cholesterol Education Program (2001) Executive summary of the third report of the National Cholesterol Education Program (NCEP) Expert Panel on Detection, Evaluation, and Treatment of High Blood Cholesterol in Adults (Adult Treatment Panel III). JAMA 285, 2486-2497.

20. Reed J (2002) Cranberry flavonoids, atherosclerosis and cardiovascular health. Crit Rev Food Sci Nutr 42, 301-316.

21. Ruel G, Pomerleau S, Couture P, Lamarche B \& Couillard C (2005) Changes in plasma antioxidant capacity and oxidized low-density lipoprotein levels in men after short-term cranberry juice consumption. Metabolism 54, 856-861.

22. Castilla P, Echarri R, Davalos A, et al. (2006) Concentrated red grape juice exerts antioxidant, hypolipidemic, and antiinflammatory effects in both hemodialysis patients and healthy subjects. Am J Clin Nutr 84, 252-262.

23. Aviram M, Dornfeld L, Rosenblat M, Volkova N, Kaplan M, Coleman R, Hayek T, Presser D \& Fuhrman B (2000) Pomegranate juice consumption reduces oxidative stress, atherogenic modifications to LDL, and platelet aggregation: studies in humans and in atherosclerotic apolipoprotein E-deficient mice. Am J Clin Nutr 71, 1062-1076.

24. Holvoet P (1999) Role of oxidatively modified low density lipoproteins and anti-oxidants in atherothrombosis. Expert Opin Invest Drugs 8, 527-544.

25. Parthasarathy S, Santanam N, Ramachandran S \& Meilhac O (1999) Oxidants and antioxidants in atherogenesis. An appraisal. J Lipid Res 40, 2143-2157.

26. Sun J, Chu YF, Wu X \& Liu RH (2002) Antioxidant and antiproliferative activities of common fruits. J Agric Food Chem $\mathbf{5 0}$, $7449-7454$.

27. Hakkinen SH, Karenlampi SO, Heinonen IM, Mykkanen HM \& Torronen AR (1999) Content of the flavonols quercetin, myricetin, and kaempferol in 25 edible berries. J Agric Food Chem 47, 2274-2279.

28. Duthie SJ, Jenkinson AM, Crozier A, Mullen W, Pirie L, Kyle J, Yap LS, Christen P \& Duthie GG (2005) The effects of cranberry juice consumption on antioxidant status and biomarkers relating to heart disease and cancer in healthy human volunteers. Eur J Nutr 45, 113-122.

29. Coimbra SR, Lage SH, Brandizzi L, Yoshida V \& da Luz PL (2005) The action of red wine and purple grape juice on vascular reactivity is independent of plasma lipids in hypercholesterolemic patients. Braz J Med Biol Res 38, $1339-1347$.

30. Flamini R (2003) Mass spectrometry in grape and wine chemistry. Part I: polyphenols. Mass Spectrom Rev 22, $218-250$.

31. Hodgson JM, Puddey IB, Mori TA, Burke V, Baker RI \& Beilin LJ (2001) Effects of regular ingestion of black tea on haemostasis and cell adhesion molecules in humans. Eur J Clin Nutr $\mathbf{5 5}, 881-886$.

32. Sung H, Min WK, Lee W, Chun S, Park H, Lee YW, Jang S \& Lee DH (2005) The effects of green tea ingestion over four weeks on atherosclerotic markers. Ann Clin Biochem 42, 292-297.

33. Lee W, Min WK, Chun S, Lee YW, Park H, Lee do H, Lee YK \& Son JE (2005) Long-term effects of green tea ingestion on atherosclerotic biological markers in smokers. Clin Biochem 38, 84-87.

34. Blanco-Colio LM, Valderrama M, Alvarez-Sala LA, et al. (2000) Red wine intake prevents nuclear factor-kappaB activation in peripheral blood mononuclear cells of healthy volunteers during postprandial lipemia. Circulation 102, $1020-1026$. 
35. Choi JS, Choi YJ, Park SH, Kang JS \& Kang YH (2004) Flavones mitigate tumor necrosis factor-alpha-induced adhesion molecule upregulation in cultured human endothelial cells: role of nuclear factor-kappa B. J Nutr 134, 1013-1019.

36. Leiro J, Arranz JA, Fraiz N, Sanmartin ML, Quezada E \& Orallo F (2005) Effect of cis-resveratrol on genes involved in nuclear factor kappa B signaling. Int Immunopharmacol 5, 393-406.

37. Kaplan S, Morgan JA, Bisleri G, Cheema FH, Akman HO, Topkara VK \& Oz MC (2005) Effects of resveratrol in storage solution on adhesion molecule expression and nitric oxide synthesis in vein grafts. Ann Thorac Surg 80, 1773-1778.

38. Bagchi D, Bagchi M, Stohs S, Ray SD, Sen CK \& Preuss HG (2002) Cellular protection with proanthocyanidins derived from grape seeds. Ann N Y Acad Sci 957, 260-270.

39. Youdim KA, McDonald J, Kalt W \& Joseph JA (2002) Potential role of dietary flavonoids in reducing microvascular endothelium vulnerability to oxidative and inflammatory insults. J Nutr Biochem 13, 282-288.

40. Kopp E \& Ghosh S (1994) Inhibition of NF-kappa B by sodium salicylate and aspirin. Science 265, 956-959.

41. Weber C, Erl W, Pietsch A \& Weber PC (1995) Aspirin inhibits nuclear factor-kappa B mobilization and monocyte adhesion in stimulated human endothelial cells. Circulation 91, 1914-1917.

42. Grundy SM, Brewer HB Jr, Cleeman JI, Smith SC Jr \& Lenfant C (2004) Definition of metabolic syndrome: report of the National Heart, Lung, and Blood Institute/American Heart Association conference on scientific issues related to definition. Arterioscler Thromb Vasc Biol 24, e13-e18.

43. Malik S, Wong ND, Franklin SS, Kamath TV, L'Italien GJ, Pio JR $\&$ Williams GR (2004) Impact of the metabolic syndrome on mortality from coronary heart disease, cardiovascular disease, and all causes in United States adults. Circulation 110, 1245-1250.

44. Aviram M \& Dornfeld L (2001) Pomegranate juice consumption inhibits serum angiotensin converting enzyme activity and reduces systolic blood pressure. Atherosclerosis 158, 195-198.
45. Park YK, Kim JS \& Kang MH (2004) Concord grape juice supplementation reduces blood pressure in Korean hypertensive men: double-blind, placebo controlled intervention trial. Biofactors 22, 145-147.

46. Reshef N, Hayari Y, Goren C, Boaz M, Madar Z \& Knobler H (2005) Antihypertensive effect of sweetie fruit in patients with stage I hypertension. Am J Hypertens 18, 1360-1363.

47. Honsho S, Sugiyama A, Takahara A, Satoh Y, Nakamura Y \& Hashimoto K (2005) A red wine vinegar beverage can inhibit the renin-angiotensin system: experimental evidence in vivo. Biol Pharm Bull 28, 1208-1210.

48. Vlachopoulos C, Aznaouridis K, Alexopoulos N, Economou E, Andreadou I \& Stefanadis C (2005) Effect of dark chocolate on arterial function in healthy individuals. Am J Hypertens 18, $785-791$.

49. Stein JH, Keevil JG, Wiebe DA, Aeschlimann S \& Folts JD (1999) Purple grape juice improves endothelial function and reduces the susceptibility of LDL cholesterol to oxidation in patients with coronary artery disease. Circulation 100, $1050-1055$.

50. Kurowska EM, Spence JD, Jordan J, Wetmore S, Freeman DJ, Piche LA \& Serratore P (2000) HDL-cholesterol-raising effect of orange juice in subjects with hypercholesterolemia. Am $J$ Clin Nutr 72, 1095-1100.

51. Freedman JE, Parker C 3rd, Li L, Perlman JA, Frei B, Ivanov V, Deak LR, Iafrati MD \& Folts JD (2001) Select flavonoids and whole juice from purple grapes inhibit platelet function and enhance nitric oxide release. Circulation $\mathbf{1 0 3}$, 2792-2798.

52. Keevil JG, Osman HE, Reed JD \& Folts JD (2000) Grape juice, but not orange juice or grapefruit juice, inhibits human platelet aggregation. $J$ Nutr 130, 53-56.

53. O'Byrne DJ, Devaraj S, Grundy SM \& Jialal I (2002) Comparison of the antioxidant effects of Concord grape juice flavonoids alpha-tocopherol on markers of oxidative stress in healthy adults. Am J Clin Nutr 76, 1367-1374. 